\title{
"Orientation" as a Sensitizing Concept in Social Work
}


Abstract

tudying institutional discourses between clients and social workers could strengthen reflections on social work practices by asking: What definitions of the situation do the $\checkmark$ partners talk from? What content do the partners wish to communicate and could there be considerable differences between the two of them? Why are the partners using specific forms of talk and what does that meta-communicate? Are they developing working agreements and tuning into each other or are communication complicated by contributors speaking from diverse footing and frames? This article explores some of these issues.

Orientation, a sensitizing concept on an intermediate level, can be considered as metaphor for being located both within the micro and macro level of the discourse. It is a concept and an analytical tool for analysing the meaning that considers different perspectives on conversational topics and forms of talk. Inspired by grounded theory and its insistence of making theory out of practice, it was through the empirical study of the discourses at Norwegian social welfare, and not through theories, that the concept orientation emerged. In analysing conversations between clients and social workers this article identifies four different types of mutual orientations: Rule-, advisory-, explorative- and cooperative orientation. The article aims at exploring the interconnection between motivations, interactions and structures in talk in social work.

\section{Introduction}

Social work is mainly 'invisible' work (Pithouse, 1998:5). Social workers meet with clients without being observed by colleagues: the results of social workers' interventions are uncertain and ambiguous and practitioners do not usually account for the helping or controlling processes in which they are involved.

'Change' is a term often used in social work settings to describe what social workers aim to achieve through their professional work. This notion of 'change' can create the impression that the social worker alone can create change; and by this may appear to be intrusive and imperialistic toward the client. Instead of talking about the social worker, in generic terms, as a change agent (Pincus \& Minahan, 1973) a better fit with the realities of social work in practice would be to call him or her a negotiator or one who negotiate change (see for example Jokinen \& Juhila, 1997; Linell \& Fredin, 1995; Oltedal, 2004).

The venture on which I am embarked in this article is to introduce the sensitizing concept 'orientation' as a metaphor and an analytical tool to increase the potential for reflection about what happens when a social worker and a client meet and talk face-to-face in an institutional setting (for the concept institutional setting see Drew \& Heritage, 1992). In so doing, I intend to recognize the importance of negotiation between client and social worker. I stress the social worker as a negotiator in a dialogical perspective (Linell 1998) rather than as a more one dimensional change agent.

An 'orientation' is a system of meaning, a frame (see for example: Goffman, 1974:1) and a definition of a situation. A related concept is 'footing' as suggested by Goffman (1981) and can be understood as a position taken by an individual within interaction. A switch of footings can occur when, for example, frames as purposes that provide meaning, contexts and participant's roles in an interaction change. 'Footing' is focused upon how we receive an utterance when we are involved in multiple positions within different frameworks. When footings are altered: 'A continuum must be considered, from gross changes in stance to the most subtle shift in tone that can be perceived' (Goffman 1981:128).

Social workers and clients may agree upon what they speak about or what words are used - but 
the meaning of what is said, changes according to differing orientations during and with in a conversation. Orientation is here defined as the definitional of the situation, the attitude or the footing of the social worker and client towards a specific conversational topic (on footing, see Goffman 1981). The social worker and client may share the orientation, or they may simultaneously use two different orientations towards the topic. Orientation may be associated with another metaphor 'the definition of the situation' and according to the Thomas theorem 'The way you define a situation, it becomes real in its consequences'.

Orientations imply different cognitive frames, that is, perspectives on the topic. For instance the topic of money, a typical focus for talk in the social welfare office, can be discussed in many different ways and with various meanings. Atypical conversation on the topic can take form of the social worker advising the client to spend money in a certain way, another can consist of an in depth conversation on how the client experiences being poor.

Different orientations also imply using different formats of talk (see: Bergmann, 1992: Silverman, 1997). Sometimes the conversation will consist of question and answer as in the 'reply' format. At other times, more common with an advice giving format, is atypical reaction to an utterance as response rather than a full reply. A further possibility is the 'fishing' format when the social worker allows the client display her or his perspective, for instance by telling one side of the story, to trigger the delivery of a similar story from the client.

Structuring processes are associated with meaning potentials, discourses and cultural norms that exist prior to actual face to face meetings, but would not exist without a living historical continuity of interactions (Linell, 1998:60). For example, what is regarded as contextual and global framing of talk in social work, such as rule - and advisory approach provides a structure for talk about social work at a social welfare office. In Norwegian social work literature there is a long lasting tradition for dividing the work with clients in two directions: administration and therapy (Christiansen, 1977; Ranger; 1986, Oltedal, 1988 and Terum, 2003). First, administration: the tradition of administration of social policy and social welfare laws, when the social worker has the power to implement what material help the client will get, can be identified as rule-orientation. Second therapy: the other tradition regarding therapy has been much more unclear. One proposal has been to work with the emotional part of the problem through helping the client with her/his self-esteem (Christiansen, 1977).

An early discussion about orientations in social work is found in 'Social Workers' Orientations: an Action Perspective' (Whittington, 1977). This article was primarily an attempt to derive a picture of orientations from the views, experiences and intentions of the social workers themselves, by categorising their subjective meanings of situations and conversations. This path is slightly different from that taken in this article as here the emphasis is on 'orientation' as linked to the client social worker relationship as it is actually practiced. Hence, the intention is to identity orientations as found in the interactional patterns, rather than in the accounts of the social workers. One reason for this approach is that some of the task-related interaction between client and social worker seems not to have been recognised at all in accounts of social workers' subjective perspectives.

In the following, empirical material is presented and a methodological approach of studying sensitizing of processes is focused to identify orientations within discourses. Four such work orientations are presented and analysed - episodes from encounters at social welfare. In the final part ordinary dialogues between social workers and clients are framed as working relationships. All categorisation work is context specific and therefore an examination of how things are done is needed in order to promote the use of reflective practices. 


\section{Method and material}

In general the Norwegian Welfare State represents a well-developed public health- and social system characterised by universal benefits (Esping-Andersen, 1990). Contrary to this, social welfare benefits are means-tested and the economic help given may vary between the 431 Norwegian municipalities. Indeed we may rather talk about a local social safety net than a national one. Social Welfare as a 'poverty agency' (see Simmel 1908) holds a position as a less predictable institution to seek help from, than other welfare institutions.

This article is based on studies of audio taped discourses between clients and social worker at Norwegian Social Welfare. The study is based on a discourse analysis of 29 audio taped conversations between clients and social workers at four social welfare offices in Norway. Nine social workers and 17 clients are involved in the study, both males and females. Among the clients are two couples. The clients have been within the social welfare system for three years or longer. The social workers have worked at the social welfare for at least three years. The material was collected in 1992. But the material is still regarded as relevant because in general, patterns between professional and users seems not to change rapidly.

I myself taped and transcribed the discourses. I have emphasized studying variations within different episodes within the discourse. 'An episode is a bounded sequence, a discourse event with a beginning and an end surrounding a space of talk, which is usually focused on the treatment of some 'problem', 'issue' or 'topic' (Linell 1998:183).

Important questions when analysing the discourses were:

- What was happening, and what seemed to be important in specific parts of the discourses?

- What did the participants do in throughout of the discourse?

More specific questions were also asked: these were concerned with forms of talk. For instance, if social worker switched between the pronouns ' $I$ ' and 'we' in ways that was not always grammatically correct. How could this grammatical form be connected to the different issues they were talking about?

Other questions where connected to the introduction of topics. When did the social worker introduce a local topic developed from a theme within this specific talk, for example talking about marriage, and when did the social worker introduce a global topic connected to social welfare mandate in the society, for example housing and economy? In other words what kind of local and global themes developed (Linell, 1998)?

To study social interaction Turner (1988) has developed what he calls a sensitizing scheme consisting of three processes:

1. Motivational processes about how people are mobilized, energized and driven to behave in various ways.

2. The interactional process is about what people actually do when they meet and influence each other.

3. The structuring process focuses on how social interaction often is repeated across time and space, and it is a mental modelling of information about what interactive sequences apply to varying types of situations.

At an analytic level it is possible to make a distinction between content, form and function. The discourse materials were interrogated using the following three questions:

1. What do they talk about?

2. How do they talk together

3. What is the purpose of their talk?

These three processes are focussed on different aspects of the discourse, footing or attitudes 
toward a conversational topic. Immediately when asked to account for what the discourse concerns, people will draw on the motivational processes and the content. Having to reflect on a meta-perspective they need to focus upon interactional processes and forms of talk. Structuring processes will appear when patterns of mutual orientations are recognised; that is different perception of the topic and different forms of talk.

The analytical process can also be described as a constant comparison between empirical text and relevant theoretical material. To use a sensitising concept as a methodological approach is to avoid the division of labelling studies as deductive or inductive, and to be aware of the ongoing process of discovering in practice through theoretical reasoning (Blumer, 1954; 1969: 46).

Transcripts of conversations between clients and social workers were coded regarding episodes, as bounded sequences. Although there was considerable overlap between some episodes regarding what kind of tasks they focused upon: four different types of tasks were identified. In some cases social workers primarily interpreted various regulations of the social welfare administration - what I call rule focused episodes. Further, I found that social workers gave advice. This advisory focus occurred in interactions where it is the client who has 'the last word' and is expected to implement the advice initiated by the social worker. There were also parts of some interactions where the aim of the talk seems to be the talk itself creating new definitions of a situation as if they are exploring something. Then there were episodes were the dialogue had a clear aim outside the talk itself. Here the focus appeared to more about being strategic toward other institutions or collaborative partners and to manage the relationships toward others. These episodes were centrally about being co-operative, when contacts outside their relation were divided.

Concepts were thereafter developed by collecting and grouping codes of task related episodes. This study did not develop the notion of theoretical reasoning further than on a 'sensitizing concepts level'. Orientation in social work as such concept was developed as a tool for exploring the connections between motives, interactions and structure in the talk at social welfare offices. These content, form and function processes may be identified as different clusters of orientations, when interaction is repeated across time and space. In different areas of professional work some patterns will be more typical than in other areas. In social work you will be able to identify this as 'third parts' in the communications between clients and social workers. One pattern will appear when they negotiate about interpreting the law, another when an advice is mediated, a third when a phenomenon within the clients' life situation is explored and a fourth when the cooperation toward others are dealt with.

I did not analyse what I identified as small-talk episodes, for example talking about the weather, in more depth. There were of course variations regarding form and content, but not as much regarding function, within a category of orientation. However, the variations were more comprehensive between orientations and therefore I found it validated for my study to divide talk at social welfare into the following four orientations.

\section{Rule orientation}

Rule orientation concerns how the social worker interprets a rule in the social welfare regulation and charter; whether or not to offer help to the client. The 'third part' in this relationship between the client and the social worker is the law. The client negotiates with the social worker on how to define his situation. But at the final stage it is the social worker who possesses the power to implement or follow up his definition of the client's needs which is related to what kind of help the society is legally offered.

The following excerpt is from the beginning of a conversation. The utterances before this 
excerpt includes the client indicating that she will talk about a delicate and tense situation when she is asking for 'food-money'.

\section{Excerpt 1}

Social worker: You can use this form actually, because it's not old. I think it was from last winter. Eh...you should... we should have an overview of your expenditure, because we're of the opinion that you should be able to manage. So... therefore

Client: It's possible maybe. But I have had so many bills lately.

Social Worker: Yes I'm sure. And we would like to have those bills documented to see what they are exactly. It is easy enough to say that 'I have had a load of bills'. And we only have it verbally from you, but we would also like to get it in writing later on. Because I think in your case you have paid most of the bills up to a certain amount, and then you've come to us. And then... I think we have been quite liberal in not demanding too much from you. But, it happens quite often now and it's well known that you get into this situation, so we would like you to get some

Client: But it's just like you're not trusting me anymore

Social Worker: Yes of course. Actually, we shouldn't trust you in any circumstances (he). We should have everything documented. It's not about trusting you or not, but it's about having to have things in writing for further processing. Our auditor monitors our procedures and they require information in writing so that they can see what's happening. And it has to be documented. So, it's not about us only. But we need you to put it in writings as well, to get it further through the system.

Client: I'll have to go to the bank and tell them what you are telling me, my bank account is overdrawn.

The client is trying to make a case, which can release a minimum sum of money. The social worker is trying to avoid this case, letting the client understand that she should dispose her money in a better way. At this point in the discourse the client does not know if she will get money or not, and at the end of the excerpt the client capitulates to the social workers definition of the situation. Later in the discourse, the social worker asks the client if she is totally out of money. The client confirms this, and then the social worker uses the client's 'old application', and gives her 'food money' for one day. The case is transferred to another social worker, with whom the client has an appointment the following day.

The social worker talked from different orientations while she was using the same word, 'we'. First is the counsellor's voice, and then it is the voice of the law, which only accepts written bills and not the oral statements of need. Locating herself in the client's position, the social worker tells the client that they have not demanded too much of her, on the contrary they have been fairly liberal with her. The client is trying to negotiate with the social worker about how to handle her present situation with many bills. By doing this, the client is intent on trying to remain within a working agreement (McCall \& Simmons, 1966:142, Goffman 1981:10) with the social worker: this means that they are staying together in the process. If the client had stopped talking, talked about something totally different, just walked out of the situation, then there would have been no working agreement. The usual way of breaking a working agreement is to stop seeking help from an agency, not meeting up next time - instead of just walking out of an ongoing encounter as that would be perceived as impolite.

When the client is being accused of misusing the system, she puts forward a strong claim toward the people at social welfare i.e. that they don't trust her. Then the social worker has 
to defend herself and show the client what kind of structure she is working within. 'Our auditor monitors our procedures and they requires information in writing so that they can see what's happening', the social worker argues. In her next footing however, the client gets the information that the social workers themselves need to have written information. The client's comment on the form and the relation made the power structure visible.

Social structure is manifested and maintained in social interaction, but the manifestation is usually hidden from the participants. To the extent that participants discuss topics, and suppress discussion of their relationship, social structure becomes invisible to them. (Scheff, 1990:185-186)

It may not be perceived to be polite to comment upon the relationship or the social workers working style within the content of such an interaction. Talking together one usually devotes oneself to the content and focus of topics under discussion.. Both the client and the social worker experience this extract as 'face- threatening. The client expresses shamefulness when she is accused of being a person who lies. The social worker utters embarrassment as she is laughing. In an institutional setting laughter appears often when the situation is tense and ambivalent (Adelswärd, 1989). When the client is saying: 'It's just like you're not trusting me anymore' this could also be characterised as if she were attempting to make a definition of the situation. From Sarangis (2000) studies of genetic counselling he concludes that explicit definitions of situations are called for at times of interactional difficulty. Findings from discourse analysis deal with the lack of fit between the institutional frame and the client frame because there are different definitions of the situation (Agar 1985: Fredin 1993).

In an utterance just after the above excerpts the client says:

'It is like going around being an insane for the rest of the day. I have been going around as an insane for a week now'.

When I listened to this on the tape I first morally accused the social worker, of not responding to what the client said. The social worker continued as if she had not heard this utterance. After reading this excerpt several times, my interpretation was that this comment could be regarded as irrelevant for the social worker as she was going to make a case about money. She was interpreting the norms and the financial situation for the client according to the existing law. The main focus in a rule orientation, is whether to give away money or not - not to empathise with the client.

This setting is globally developed. The most common reasons for clients to seek help from social welfare are because of financial problems. The text above, from a client social worker relationship, can be regarded as meaningful talk about money. The motivation for the partners in the encounter could be to focus upon what opportunities the client has to obtain the money that she is applying for. The interaction as it developed in the setting can be interpreted as the participants talking from different systems, instead of meeting each other within the 'space' created by a more holistic life world perspective. For the social worker to be able to implement this rule orientation, it is more important to 'tune into' the system than toward the client life situation.

\section{The advisory orientation}

The advisory orientation regards situations where the social worker is trying to deliver counselling and advice to the client. In this advisory orientation the social worker wants the client to do something quite specific. It considers an arena in the client's life that the social worker legally can't domain. The delivering process aims at the client's decision to follow the advice from the social worker. In principle the client should follow it or deny following it out of free will. 
In the following excerpt the social worker wants the client to queue up for an apartment. The advice, which gets the form of a directive, is given smoothly. The extract start with the social worker exploring 'where the client is' and what he thinks regarding his house situation:

\section{Excerpt 2}

Social Worker: (...) Have you given some thought to the possibility of Vik being the place you would like to stay for the rest of your life?

Client: Yes, I want to stay here. I like it here.

Social Worker: Have you thought about getting in contact with the housing cooperative, and through them, getting a one, two or three bedroom flat?

Client: Yes, I would like to do that.

Social Worker: But you haven't been there to put your name down yet?

Client: No, I haven't done that

Social Worker: Well, but it would be smart

Client: Yes, that's for sure

$(\ldots \ldots \ldots)$

Client: Yes, I'm intending to stay in this flat until I find something bigger

Social Worker: Yes, but get in contact with the housing cooperative. Hand in an application, but you don't have to take what's vacant.

Client: No, that's right, because they would know about the various vacancies, wouldn't they?

The social worker initiates this advice and believes strongly in it, he needs therefore to move carefully and not push the client too much. He is asking different question to investigate if the client is ready for his advice. He is trying to take the clients position and makes different orientations from that perspective. It is the client who can follow up the advice and the interesting thing is not the social workers opinion of what is best for the client, but to 'tune in' to the clients point of view.

The form of the talk is within an information-giving format where the social worker is doing the main part of the talk and the client is giving back-channelling responses. Research has shown that different ways of counselling whether it is called 'persuasion', 'advice-giving' or 'leading in a particular direction', tends to work most effectively when tied to a perspective actively elicited from a client (Silverman 1997:230).

In advice orientation mode, clients and social workers use a lot of different communication strategies. For example, the social worker can hold the floor for a long stretch while only demanding responses, not replies, from the client. Although the advice is delivered by the social worker, to be effective the client should interpret it and make the advice meaningful from his or her perspective.

The advice giving mode could be regarded as a typical professional situation, where the social worker performs a change agents' role. The text from the above encounter shows that there 
is a need for negotiations between client and social worker to establish a particular thematic content and a specific advice as the third part in this text. When advice is followed or not as the case may be, the process should be visible and moreover it should be possible to trace back into an action not only a change in thought.

\section{The explorative orientation}

The explorative orientation has its focus talk about a phenomenon in the client's life situation; the ambition is to create a new life-story or a new definition of their situation such that their partners anticipate a degree of change in the client's life.

This orientation has similar features to that of a therapeutic relation because the actors are creating a new story about the client's life: the focus is on the interaction and processes within the conversation. The interaction is quite open in the way that they both deliver a statement or provide input to the conversation and thereafter comment upon what was initially said in the interaction. This is a dialectic process where there is a thesis and anti-thesis and then synthesis on a higher level. This is not so much about implementing a task and getting a result visible outside the relationship, as to stay within the process and tune in towards each other. As a professional skill 'tuning in' involves the worker' making the effort to get in touch with the potential feelings and concerns that the client may bring to the helping encounter (Shulman 1992).

In the following explorative extract, the client and the social worker are discussing the client's former alcohol abuse. They are reconstructing the history by contrasting this to the situation of those who still have this problem:

\section{Excerpt 3}

Client: For it's not getting better. No, they're only hitting the bottle.

Social Worker: Yes

Client: Yes, so in that way one is having a better time now

Social Worker: Yes it must be a totally different life from what you had?

Client: Yes, yes, of course it is. It's no comparison.

Social Worker: No. (A break.) Yes, and the car must be a great help.

Client: Yes of course it is. I don't know what would happened if I didn't have

Social Worker: Yes there are many people who have survived because of their car. I know at least two or three from my age group, who couldn't manage before they got a car. One of them had his driving license taken from him for two to three years. And in that time he realized how important it was and decided he would stop drinking. Well that is thirty years back in time, at least twenty-five years ago. He hasn't touched alcohol since then.

Client: Yes, I've come to the conclusion that the best therapy is to get out and talk to people.

It is the client who initiates the discussion about alcohol abuse. He describes an account big difference in life quality previously and now. The social worker uses his own history when he is engaged in drawing out the client's story. He puts emphasis on the importance of getting a car. The client is living in a rural area and he is elaborating on how the car makes it possible 
to visit people. In the clients own words: 'Talking to people is therapy'. The point is to explore the client's situation, to be in touch with his definition of the situation and to co-create his history.

Although the social worker introduces the theme about the car, it is the client that is states this as being the important element in this story. The position they both are exploring is the client's life situation. They are both talking in a rather comprehensive manner drawing on different life experiences, meeting each other as whole persons, not only as representing different systems. The client is using 'one' instead of ' $l$ ' - to underline that the life is better now. It could be interpreted that he is generalising and then creating a stronger argument for the elements that saved him.

In the explorative orientation topics on content such as networks and health are locally developed. In the first phase of a client social worker relationship at a social welfare office, there is usually no working agreement regarding such topics, but the relationship and the confidence developed within the discussion make it possible to move into explorative orientations. A characteristic form of talk within an explorative orientation is fishing devices telling one interpretation of a story. When somebody 'tells ones' own side' this often triggers a delivery of a similar story or perhaps a more authoritative one told by the other.

The explorative setting needs to be developed locally. I discovered that a conflicting or tense relationship, never developed into an explorative orientation within the discourse. The globally developed notion of social welfare does not inform the client that this is a system they can encounter within which they are free to talk about and explore their life situation. Although, given the professional 'change-agent style' image that social workers may present, social welfare as such, as experienced, through may seem to be a positive helping social space. Further, if a client and a social worker are members of the same rural society and know each other from that stage, they may negotiate the interaction to be an explorative one. The interpretation of the text is motivated to a great extent by the necessities of the extra-textual context (Bakhtin 1986:166). To be creative and sensitive is a skill necessary for social workers to develop in an explorative orientation.

Curiosity is also a motivation to interpret and develop a text in an explorative direction. In the interaction there is a need to be sensitive to what is developed during the encounter and the structuring of the discussion should balance on the edge of private and public talk.

\section{The co-operative orientation}

The co-operative orientation deals with the client and social worker's relation toward other institutions, it can even be cooperation with another unit (or person) within their own institution. An important part of relationships between the different institutions are focused around the medium used for communication such as written paper, meetings. Similarly the definitions of core issues as the role of the worker and user in different systems shape the form and nature of communication

In the following excerpt the social worker and the client are negotiating their different positions in relation to the local job centre.

\section{Excerpt 4}

Social Worker: Is she the one (a new case-manager at the job centre) who got the case transferred from Richard (an experienced case-manager still working at the job centre) and will put effort into your case and get you a job?

Client: Richard is still the person who... She said she would give me a call. 
Social Worker: But you know Richard has a whole range of contacts, while she has just the possibilities down there.

Client: Yes, Richard said he should

Social Worker: Yes but they have got so many clients on their books, that you have to be pushy and be active your self, you see.

Client: Yes, I have phoned him

Social Worker: Yes, yes now after, after

Client: Yes

Social Worker: Great. I will have a meeting with him next week, this...this case meeting. And I will look directly at him and see if he can come up with something.

Client: I will go there

Social Worker: That's really great.

The social worker has an unequivocal opinion that Richard is the best case-manager for the client. The client can 'choose' which case-manager he will stay in contact with; while it is not considered proper behaviour for a social worker to interfere in how another institution is dealing with internal administrative matters such as of who is going to work with the different cases. It is on the other hand legitimate that a client can advocate or press his own case. The social worker however, has a better opportunity than the client, to push a case forward in cooperative and institutionalised meetings.

This extract can be interpreted as a collaborative discussion about how to divide the work that needs to be done toward another institution. The aim of this co-operative orientation is to strengthen opportunities they each have given their different positions. Together they should be able to work together to improve the client's case. A focus in this excerpt is to create attention and to establish the client's situation as unique and special for the caseworkers at the job centre. In this situation it is evident that both client and social worker have power in different areas.

In the interaction it is important to define what kind of strategic advantages each of the participants has toward developing collaborations with other institutions. Mandates and practices within different collaborative systems structure how the collaborative genre is elaborated.

\section{Discussion}

The article deals with the framing of social work interventions within discourses between social workers and clients at Norwegian welfare offices. Orientation as a sensitising concept is developed to study what is going on within this institutional setting.

Social welfare includes support and practical help that can be given to people so that they can manage their daily lives in difficult situations. Assessment of need by a professional social worker is undertaken so that every case can be treated as unique. Social workers at welfare agencies work within a challenging and demanding institutional setting. The nature of professional assessment is crucial to the understanding of why social workers still hold the 
majority of positions within social welfare in Norway. Social workers have an important role in negotiating between what they interpret as the client's needs and the mandate they have from the lawmakers.

Orientation is considered to be a metaphor for being located both within the micro and themacro situation of the discourse. Macro can here be defined as both the structuring and motivational processes (Turner 1988). Laws, ideologies, professional thinking and definitionregarding what social work is about, are frames that the social worker and the client, to amore limited degree, possess already before they enter into a specific conversation.

Orientations are such macro frames preparing the partners for the forthcoming talk. This could be to become aware of possible topics such as: the interpretation of -interpretation; the social worker looking for possibilities to initiate advice; perhaps that the client wants to just talk with the social worker about an unsolved problem. Topics may also be about the provision of information as when the clients need access to other parts of the helping systems. Micro can be considered as focusing on the interactional processes (ibid) when people meet and influence each other. The nature of the institutional frames that they talk within opens possibilities and creates restrains on what can be said and done in these meetings. But in spite of this, clients and social workers in their unique individual human context can transcend these macro frames and develop their own specific working relationship. They do this when they are tuning into each other (Shulman, 1992).

To be able to carry out an institutional discussion social work both parties need to develop role-competence. Clients can demonstrate this competence when they know what questions are relevant to ask at a social welfare office. On the other hand, the social worker need to develop professionalism within this context; what are they supposed to know something about and what is or is not their area of competence. There could of course also be a discrepancy between the social workers actual knowledge and what the client might rightfully expect of them. Then the social worker can lead the conversation into a cooperative orientation, telling the client that $s /$ he needs to seek information from others.

Changes in orientations will develop on the local level, when the client and social worker are talking together. For example, through the talk about rules a client builds an image of the social worker as competent in his/her role performance and the client moves into an explorative orientation of the talk. The social worker demonstrates her/his experience, knowledge and empathy and together they have developed a good working relationship. The client may be tense and my then start talking about a complicated issue, that require exploration to see if the discussion in itself will give her/him some new reflections that can lead to solutions of his/her problem. It is somewhat surprising that clients do not initiate advice-talking (Oltedal, 2000); a reason for this could be that it is difficult for advice-giving not to interfere with other forms, for example rule orientation. The client's freedom to follow or not follow the advice then becomes blurred.

Reflecting about the talk in different orientations may help the partners to identify what kind of power each of them possesses in any particular interaction. If the social worker has strong opinions about what is best for the client, s/he then should reflect upon what orientation contains the issue. If for example s/he does not have power to implement a legal interpretation in the relation with the client, s/he must use more power to convince the client to act in another way. Maybe s/he then will shift between advice, explorative and cooperation orientation to guide the client to get what the social worker defines as a better situation for the client.

To move between different orientations within the encounter it is important to be aware of the context and the importance of the social workers sense of functional clarity. Shulman writes: 
'A profession is not defined by its skills. It is differentiated from other professions by its functional role [...]the worker's sense of the next step at specific moments of interaction will be vitally affected by the internalized sense of function' (1992:22). Anticipations regarding role performance are to a large extent decided even before the specific client and social worker meet each other face-to-face. A minimum working agreement in the discussion between client and social workers at an institutional setting could be that they actually sit together and talk without any of them walking out or leaving the communication situation.

Most social work practice theories suggest that through the social workers activity a 'positive working relationship' can be developed with the client and this relationship is a precondition for helping (Shulman 1992: 59). Shulman`s hypothesis is that the working relationship will develop only after the purpose of the encounter has been clarified and the worker's role explicitly described. In effect, the relationship emerges from rather that precedes the work (ibid: 84). 'Working alliance' is defined as a collaborative relation that facilitates positive change and three aspects are here fundamental. The degree of agreement between professionals and clients about the aim of the treatment, the ability to cooperate to obtain these aims and the establishment of trust and mutual respect in the relationship that create a safe environment to explore relational and human problems (Andreassen, 2003:222).

Therapist characteristics were explored as possible predictors of working alliance in psychotherapy (Hersoug et al., 2001) and it is somewhat surprising that longer experience, more professional training, better professional skills, and more progress as a therapist did not have any significant impact on the working alliance as rated by patients. From the context of how child health nurses established a task oriented contact with children and parents, the concept 'joint working relationship' is introduced (Hydèn and Baggens 2004). To establish this frame a kind of emotional relationship has to be obtained. It is a temporary relationship and the nurse needs to be able to shift among different interactional modes using artefacts, verbal and nonverbal communicative means to synchronize with the child and its parents (ibid).

There is a need in social work to examine how things are done, not how they should be done. Social workers need to be able to acknowledge the capacity of their theories and assessment tools, to be able to see themselves in the act of knowledge making (Taylor \& White, 2001). Timms old critique of social work seems to be still relevant. He says that it is surprising how little social workers are interested in the role of language and talk at work when one takes into consideration the importance of words and communication in social work. 'Social workers in training are often encouraged not to accept 'at face value' what their clients say, and to see themselves as 'getting behind' the words the client use' (Timms 1968:3). There is a need to validate what is going on in the talk in itself, and to be aware of what is being communicated. This may be a different interpretation from focusing on what is going on according to social work practice theories and norms within a welfare system. There is a need to be more reflective upon and sensitive about what we take for granted regarding client and social work positions in different social work practices. We encounter a specific meeting with prior opinion of what is going to happen.

The deeply contextual nature of social work differentiates it from other professions (Healy 2005:4). Contextual sensitivity helps us to focus upon how the same phenomenon affects the family, women, or those who live in poverty, and as a consequence they will get various interpretations in different contexts (Silverman 2001: 9). We need to recognize that all categorisation work is context specific.

\section{References:}

Adelswärd, V. (1989) Laughter and dialogue. Nordic Journal of Linguistics, nr.12 
Agar, M. (1985) Institutional discourse, Text. 5(3):147-168.

Andreassen, T. (2003) Behandling av ungdom i institusjoner Hva sier forskningen? Oslo: Kommuneforlaget.

Bahktin, M. (1986) The Problem of Speech Genres. In: M. Bakhtin Speech genres and other late essays. Austin Texas: University of Texas Press.

Bergmann, J.R. (1992) Veiled morality: Notes on discretion in psychiatry. In: Drew, Paul and John Heritage: Talk at work. Interaction in institutional settings. Cambridge: Cambridge university press.

Blumer, H. (1954): What is wrong with social theory? I: American sociological review. 19, ( 1)

Drew, P. Heritage, J. (1992). Talk at work. Interaction in institutional settings. Cambridge University Press.

Esping-Andersen, G. (1990) The Three Worlds of Welfare Capitalism. Oxford: Polity Press and Blackwell.

Fredin, E. (1993): Dialogen i socialt arbete. SIC 36, University of Linköping. Studies in Communication.

Hersoug, A.G., P. Höglend, J. T. Monsen and O. E. Havik (2001): Quality of Working Alliance in Psychotherapy. Journal of Psychotherapy Practice and Research. 10: 205-216,

Goffman, E. (1974): Frame analysis. Northeastern University Press.

Goffman, E. (1981): Forms of talk. Basil Blackwell.

Healy, K. (2005): Social Work Theories in Context. Basingstoke: Palgrave Macmillan.

Hydèn, L-C and C. Baggens (2004): Joint working relationships: Children, parents and child healthcare nurses at work. Communication \& Medicine 1(1):71-83.

Jokinen, A \& K. Juhila (1997): Social work as negotiation. Constructing Social Problems and Clienthood. In: Nordisk sosialt arbeid nr. 3

Linell, P. (1998): Approaching Dialogue. Talk, interaction and contexts in dialogical perspectives. IMPACT 3 Studies in Language and Society. Amsterdam/Philadelphia: John Benjamins Publishing Company.

Linell, P. \& E. Fredin (1995): Negotiating Terms in Social Welfare office Talk. In: Firth, A. (ed.) The Discourse of Negotiation. Studies of Language in the Workplace. Great Yarmouth, Pergamon.

McCall, G.J. and J.L. Simmons (1966): Identities and interactions. New York: The free press. Oltedal, S. (2000): Praksis i sosialt arbeid. Ei studie av klientsamtalar på sosialkontor. Dr.polit.avhandling Trondheim: NTNU.

Oltedal, S. (2004): Klientsamtalar innan velferdsstaten. Bergen: Fagbokforlaget.

Pincus, A. and A. Minahan (1973): Social Work Practice: Model and Method. Itasca, III: Peacock. 
Pithouse, A (1998): Social Work: The Social Organisation of an Invisible Trade. Second edition. Ashgate, Aldershot, Brookfield.

Sarangi, S. (2000) Activity types, discourse types and interactional hybridity: the case of genetic counselling. In Skrikant Sarangi and Malcolm Coulthard, (eds) Discourse and Social Life (eds). London: Longman.

Shulman, L. (1992) The skills of Helping Individuals, Families and Groups (Third Edition) Itasca Illinois: F.E. Peacock Publishers inc.

Scheff, T.J. (1990): Microsociology. Discourse, Emotion, and Social Structure. Chicago; The University Press of Chicago Press.

Schutz, A (1972) Hverdagslivets sociologi. København: Hans Reitzel Forlag oversatt:2005.

Silverman, D. (1997) Discourses of counselling. London: Sage.

Silverman, D. (2001) Interpreting Qualitative Data Second Edition London: Sage.

Simmel, G. (1908): The Poor. In G. Simmel, G (1971) On individuality and social forms. The University of Chicago press.

Taylor, C. and S. White (2001): Knowledge, Truth and Reflexivity. The problem of Judgement in Social Work. Journal of Social Work 1(1): 37-59.

Timms, N. (1968) The Language of Social Casework. London: Routledge \& Kegan Paul.

Turner, J.H. (1988) A theory of Social Interaction. Stanford University Press, USA

Whittington, C. (1977) Social Workers` Orientations: an Action Perspective in The British Journal of Social Work. 7(1): 73-95. 